\author{
Jurnal Aplikasi dan Inovasi Ipteks "SOLIDITAS" \\ Vol. 1 / No. 1 / April 2018 ; 15-23 \\ ISSN 2620-5076
}

\title{
PERENCANAAN PEMELIHARAAN POMPA HIDRAM DI DESA NGADIRESO, PONCOKUSUMO-MALANG
}

\author{
Diah Wilis L.B ${ }^{1)}$; Febi Rahmadianto ${ }^{2)}$; Widiyanto Hari S.W ${ }^{3)}$ \\ Fakultas Teknologi Industri Institut Teknologi Nasional Malang ${ }^{1,2,3)}$ \\ Email : wilis.basuki@lecturer.itn.ac.id ${ }^{1)}$
}

\begin{abstract}
ABSTRAK
Desa Ngadireso Kec. Poncokusumo Kabupaten Malang terdiri dari 5 dusun. Di antara kelima Dusun tersebut adalah Dusun Ngadireso dan Dusun Putuk. Desa Ngadireso terletak dikaki gunung semeru bagian barat dan berada disebelah timur Kabupaten Malang. Wilayah Desa Ngadireso merupakan daerah berbukit-bukit yang merupakan konsekwensi dari wilayah kaki gunung, sehingga berimplikasi pada penyediaan air untuk kebutuhan masyarakat yang tinggal didaerah perbukitan. Jarak Desa Ngadireso dari pusat kota $\pm 52 \mathrm{~km}$, sedangkan dari kampus ITN Malang sekitar \pm 44 $\mathrm{km}$. Kebutuhan air bersih di desa ini telah dipenuhi oleh pompa air secara konvensional yaitu pompa hidram. Adapun jumlah pompa hidram yang ada sebanyak dua buah, berasal dari PNPM Mandiri dan pihak terkait. Untuk itu agar mendapatkan kwantitas air yang stabil perlu diadakan proses perbaikan dan perawatan yang tepat serta pengelolaannya. Pompa air yang digunakan masyarakat Dusun Ngadireso terdapat dua pompa hidram yang dibiayai oleh PNPM Mandiri dan sumbangan dari pihak terkait, untuk itu perlu diadakan proses penyuluhan tentang perbaikan dan perawatan serta pengelolaan sehingga akan didapatkan biaya perawatan yang ringan, sehingga tidak akan menjadi beban masyarakat. Dengan demikian diperlukan informasi terkait operasional perbaikan pompa hidram dan mendapatkan perawatan yang murah. Dari kondisi daerah dan masalah yang dihadapi, maka dengan dilakukannya program perawatan dan pemeliharaan pompa hidram secara berkelanjutan akan megurangi biaya lebih dari perawatan pompa hidram dan mengurangi tingkat kerusakan yang berlebihan. Program Pelatihan pompa hidram mampu memberikan pemahaman dan skill yang lebih baik buat masyarakat dalam memelihara pompa hidram.
\end{abstract}

Kata kunci: pompa hidram, manajemen pengelolaan

\begin{abstract}
Village Ngadireso Kec. Poncokusumo Malang Regency consists of 5 hamlets. Among the five villages are Dusun Ngadireso and Dusun Putuk. Ngadireso village is located on the western mountain of Semeru and is east of Malang regency. Ngadireso Village area is a hilly area that is a consequence of the foot of the mountain, so it implies the provision of water for the needs of people living in the hills. Ngadireso village distance from the city center $\pm 52 \mathrm{~km}$, while from the campus ITN Malang about $\pm 44 \mathrm{~km}$. The need for clean water in this village has been met by a conventional water pump, which is a hydra pump. The number of existing hydram pumps as much as two, comes from PNPM Mandiri and related parties. Therefore, in order to obtain a stable quantity of water needs to be carried out the process of repair and proper maintenance and management. The water pump used by Ngadireso Hamlet community consists of two hydram pumps funded by PNPM Mandiri and donations from related parties. Therefore, it is necessary to conduct a counseling process on the improvement and maintenance and management so that there will be a low maintenance cost so that it will not become the burden of the community. Therefore, information related to hydrothermal pump operation is required and get cheap maintenance. From the local conditions and problems encountered, the continuous maintenance and maintenance program of hydram pumps will reduce the cost of hydrothermal pump maintenance and reduce excessive damage. Hydram pump training program is able to provide better understanding and skills for the community in maintaining hydra pumps.
\end{abstract}

Keywords: Hydraulic Pump Repair and Treatment, Management Management 
Wilis, Perencanaan Pemeliharaan Pompa Hidram..

\section{PENDAHULUAN}

Desa Ngadireso Kec. Poncokusumo Kabupaten Malang terdiri dari 5 dusun. Di antara kelima Dusun tersebut adalah Dusun Ngadireso dan Dusun Putuk. Desa Ngadireso terletak dikaki gunung semeru bagian barat dan berada disebelah timur Kabupaten Malang. Wilayah Desa Ngadireso merupakan daerah berbukit-bukit yang merupakan konsekwensi dari wilayah kaki gunung, sehingga berimplikasi pada penyediaan air untuk kebutuhan masyarakat yang tinggal didaerah perbukitan. Jarak Desa Ngadireso dari pusat kota $\pm 52 \mathrm{~km}$, sedangkan dari kampus Institut Teknologi Nasional (ITN) Malang $\pm 44 \mathrm{~km}$.

Desa Nadireso Kec. Poncokusumo memiliki sumber air yang cukup besar dengan debit 1 $\mathrm{m}^{3} /$ menit. Pemanfaatan air yang berasal dari sumber air umbulan Dusun Ngadireso yaitu untuk memenuhi kebutuhan rumah tangga, pertanian dan sisanya dialirkan ke sungai Ngadireso.

Pemanfaatan air untuk kebutuhan rumah tangga, masyarakat awalnya mengambil air menggunakan jerigen bagi penduduk yang jauh tempat tinggalnya, sedangkan yang dekat melakukannya dengan menggunakan ember.

Dalam perkembangannya masyarakat mengadakan mesin pompa dengan penggerak motor listrik. Biaya awal untuk pengadaan pompa dan motor listrik, dimana masyarakat harus mengeluarkan biaya sebesar Rp. 600.000,- untuk setiap kepala keluarga (KK). Sedangkan untuk biaya bulanan masyarakat dikenakan Rp. 9.000,-/KK dan untuk rumah tangga yang juga digunakan untuk usaha dikenakan Rp.350.000,-. Kondisi ini sangat membantu masyarakat dalam memperoleh air, namun biaya operasional dan perawatannya cukup tinggi.

Adapun untuk biaya perawatan ringan sebesar Rp. 800.000,-, sedangkan untuk membayar listrik sebesar \pm Rp. 5.000.000,- setiap bulannya. Pendapatan yang diperoleh dari iuran masyarakat perbulan \pm Rp. 6.000.000,-, sehingga cukup untuk biaya perawatan ringan dan pembayaran listrik. Kesulitan terjadi jika terjadi perawatan berat, dimana perawatan yang terjadi memerlukan biaya yang cukup besar yaitu sebesar \pm Rp. 4.000.000,-.

Pompa air yang sekarang ada bekerja untuk memompa air dari sumber air menuju tandon dengan ketinggian $100 \mathrm{~m}$ dengan kemiringan $30^{\circ}$ dari garis vertikal dan mempunyai debit pompa sebesar 7 ltr/detik atau 42 liter/menit. Dari tandon air baru dialirkan kerumah-rumah penduduk dengan jarak terjauh $\pm 650 \mathrm{~m}$. Dengan debit yang kecil terasa sangat kurang bagi masyarakat dengan jumlah penduduk $413 \mathrm{KK}$ dengan jumlah penduduk \pm 1500 orang untuk dusun Putuk, sedangkan untuk Dusun Ngadireso sebesar 650 KK dengan jumlah penduduk \pm 1800 orang. Tidak semua penduduk memanfaatkan air melalui pompa air dari sumber mata air, sebagian kecil penduduk yang kaya sekitar $\pm 10 \mathrm{KK}$ memilih untuk mengebor sendiri dengan kedalaman $\pm 90 \mathrm{~m}$. Untuk masyarakat yang menengah kebawah lebih memilih menggunakan sumber air yang dipompa ke rumah penduduk, dengan biaya yang ditanggung bersama walaupun terasa berat.

Mutu air dari sumber air umbulan sudah pernah dilakukan pengujian laboratorium oleh Departemen Kesehatan Kabupaten Malang dengan hasil layak untuk dimanfaatkan oleh masyarakat dalam memenuhi kebutuhan rumah tangga (hasil wawancara dengan warga).

Dari analisis situasi dan justifikasi prioritas masalah yang disepakati mitra untuk diselesaikan, maka memiliki beberapa solusi yang ditawarkan:

a. Dari kondisi daerah dan masalah yang dihadapi, maka diperlukan perbaikan dan perawatan dalam menggunakan pompa Hidram.

b. selain itu perlu dilakukan manajemen/pengelolaan air bersih yang diproduksi agar didapatkan perawatan pompa hidram yang murah.

Dari kedua hal tersebut, maka bentuk kongkrit dari solusi yang ditawarkan dan diaplikasikan dalam beberapa bentuk kegiatan. 
Jurnal Aplikasi dan Inovasi Ipteks, Vol. 1 / No. 1 / April 2018 ; 1-10

\section{METODE}

Metode pelaksanaan yang dilaksanakan pada kegiatan ini berdasarkan permasalahan warga desa dusun Ngadireso dalam penggunaan pompa hidram terbagi kedalam 3 permasalahan bidang, antara lain:

\section{Permasalahan Bidang Perbaikan dan Perawatan}

Langkah-langkah dalam menyelesaikan permasalahan bidang Perbaikan dan Perawatan antara lain:

a. Koordinasi dan diskusi dengan warga tentang cara kerja Pompa Hidram.

b. Produksi air bersih yang dihasilkan oleh pompa hidram dalam waktu satu hari.

c. Pengecekan Komponen-komponen pompa hidram yang tidak berfungsi

d. Pelatihan melakukan Perbaikan dan Perawatan terhadap pompa hidram.

e. Evaluasi.

\section{Permasalahan Bidang Manajemen Pengelolaan}

Langkah-langkah dalam menyelesaikan permasalahan bidang Manajemen Pengelolaan antara lain:

a. Koordinasi dan diskusi dengan warga tentang Distribusi Air.

b. Produksi air bersih yang dihasilkan oleh pompa hidram dalam waktu satu hari.

c. Kondisi Pengelolaan yang ada pada saat ini

d. Pelatihan melakukan manajemen pengelolaan pompa hidram dengan baik.

e. Evaluasi.

Dalam menyelesaikan persoalan warga dusun ngadireso perihal perbaikan dan perawatan serta manajemen pengelolaan yang telah disepakati bersama tim pengabdian dalam kurun waktu realisasi program pengabdian masyarakat yaitu dengan melakukan kunjungan dan pelatihan di dusun ngadireso Poncokusumo Kabupaten Malang.

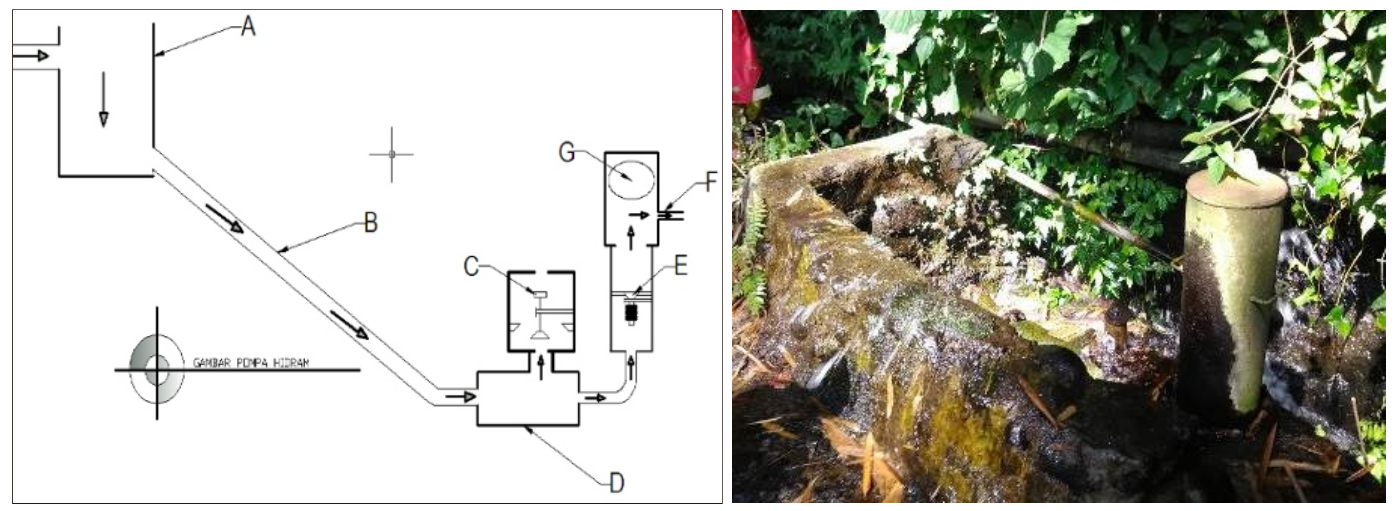

Gambar 1. Pompa Hidram

Keterangan gambar :

A. Water Source Tank

B. $\quad$ Pipa Masuk (Drive Pipe)

C. Katup Buang (Waste Valve)

D. Badan Hidram

E. Katub Penghantar

F. Pipa Penghantar (Delivery Pipe)

G. Tabung udara 


\section{Pompa Hidram}

Pompa hidram atau singkatan dari hydraulic ram yang berasal dari kata Hidro = air (cairan), dan Ram = hantaman, pukulan atau tekanan, sehingga terjemahan bebasnya menjadi tekanan air. Jadi pompa hidram adalah sebuah pompa yang energi atau tenaga penggeraknya berasal dari tekanan atau hantaman air yang masuk kedalam pompa melalui pipa. Masuknya air yang berasal dari berbagai sumber air ke dalam pompa harus berjalan secara kontinyu atau terus menerus.

Alat ini sederhana dan efektif digunakan pada kondisi yang sesuai dengan syarat-syarat yang diperlukan untuk operasinya. Dalam kerjanya alat ini, tekanan dinamik yang ditimbulkan memungkinkan air mengalir dari tinggi vertical (head) yang rendah ke tempat yang lebih tinggi.

Penggunaan hidram tidak terbatas hanya pada penyediaan air untuk kebutuhan rumah tangga, tapi juga dapat digunakan untuk pertanian, peternakan, dan perikanan darat. Karena pompa ini bekerja tanpa menggunakan bahan bakar minyak (BBM) atau tanpa motor listrik maka disebut juga "Pompa Air Tanpa Motor"(Motorless Water Pump) dan disingkat PATM.

\section{Prinsip Kerja}

Prinsip kerja pompa hidram adalah melipatgandakan kekuatan pukulan air pada rumah pompa, sehingga terjadi perubahan energi kinetik menjadi tekanan dinamik yang mengakibatkan terjadinya palu air (water hammer) dan terjadi tekanan tinggi di dalam pompa. Palu airr adalah hentakan tekanan atau gelombang air yang disebabkan oleh energi kinetik air dalam gerakannya ketika tenaga air ini dihentikan atau arahnya diubah secara tiba-tiba. Tekanan dinamik diteruskan ke dalam tabung udara yang berfungsi sebagai penguat tekanan air dan memaksa air naik ke pipa penghantar.

Walt (1981) berpendapat bahwa pada sistem pemompaan pompa hydram, peristiwa palu air ini terjadi karena air yang mengalir dalam pipa dengan kecepatan masuk ke dalam sistem pompa naik ke waste valve, sehingga terjadi penutupan tiba-tiba dan menyebabkan timbulnya tekanan yang cukup besar dalam badan pompa. Gelombang tekanan air yang terjadi akibat palu air diteruskan ke dalam tabung udara yang berfungsi sebagai tabung kompresor melalui delivery valve.

Siklus pemompaan pompa dapat dibagi menjadi empat periode, yang didasarkan pada posisi katup pembuangan seperti yang terlihat pada Gambar dibawah ini:

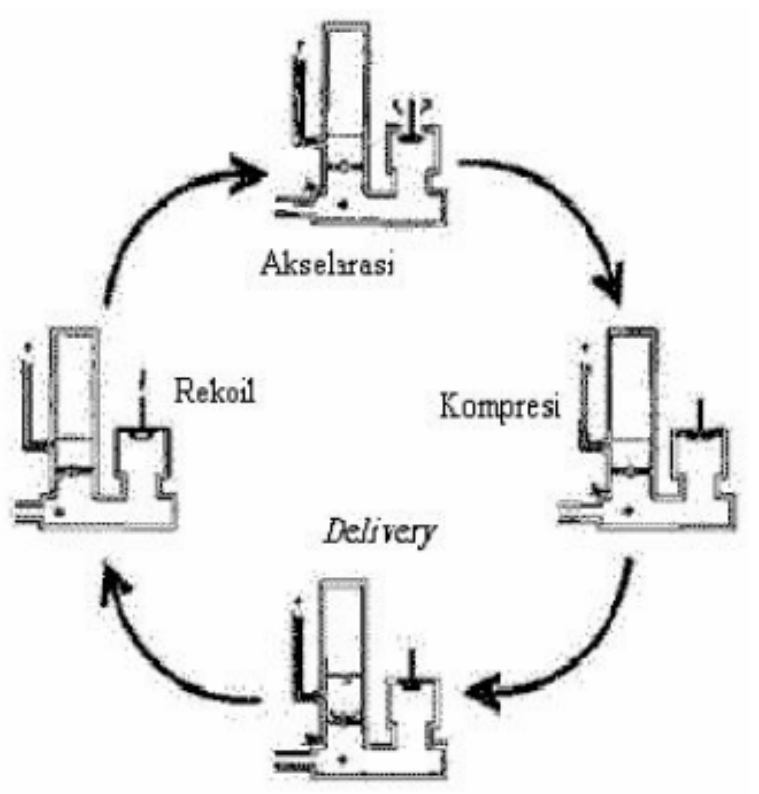

Gambar 2. Siklus Pemompaan Pompa Hidrolik (Suroso dkk Oktober 2012). 
Dengan urutan penjelasan langkah sebagai berikut :

a. Akselerasi: Katup pembuangan terbuka dan air mulai mengalir dari sumber dan keluar melalui katup pembuangan. Aliran mengalami percepatan akibat pengaruh ketinggian sumber $(\mathrm{h})$, sampai kecepatan nol dicapai di dalam pipa penggerak.

b. Kompresi: Katup pembuangan terus menutup dan akhirnya tertutup penuh, dan pada saat itu air bergerak sangat cepat dan tiba-tiba kesegala arah yang kemudian menimbulkan energi potensial yang berubah menjadi energi tekan.

c. Penghantar: Katup pembuangan tertutup penuh dan tetap tertutup. Penutupan tiba-tiba mengakibatkan tekanan yang tinggi di dalam hidram dan pada check valve yang melebihi tekanan penyaluran statis. Katup kendali didorong terbuka dan pemompaan berlangsung sampai kecepatan maksimum dan proses pemompaan berhenti, dibawah pengaruh perlambatan head tekanan penyaluran.

d. Rekoil: Katup penyaluran tertutup. Tekanan dekat tekanan katup kendali jauh lebih tinggi dari pada tekanan sumber statis dan aliran balik terhadap sumber aliran. Peristiwa ini disebut kegiatan pembalikan. Peristiwa pembalikan mengakibatkan ruang vakum di hidram, secara temporer mendorong sejumlah kecil udara dihisap masuk ke dalam hidram melalui katup udara. Tekanan pada bagian bawah katup pembuangan juga terkurangi dan bersamaan dengan pengaruh beratnya sendiri, katup pembuangan membuka secara otomatis. Air di dalam pipa penggerak kembali ke tekanan sumber statis sebagaimana sebelumnya dan siklus berikutnya dimulai. Peristiwa ini secara otomatis diulang pada saat pemompaan.

\section{Tinjauan Pustaka}

Pada 2013, Habli, telah melakukan penelitian untuk menganalisis peran manajerial pengelolaan air. Yang mengarah pada kesimpulan, bahwa pengelolaan air harus ada disemua bagian karena manajemen yang tidak terkoordinasi dan tidak terlatih dapat menurunkan kualitas air.

Selanjutnya pada tahun 2016, Siswati telah melakukan penilaian manajemen air limbah domestik terpusat. Kriteria manajemen terdiri dari manajemen kinerja, teknis, kelembagaan, peraturan, pembiayaan dan partisipasi publik. Menggunakan metode SEM, dan menghitung setiap kriteria dengan ANP; hasil yang cocok adalah manajemen kinerja dengan 75,37\%. Selain itu, penulis menemukan bahwa prioritas perhatian dalam sub kriteria global adalah keberlanjutan, butuh $48,20 \%$ secara

\section{Komponen Utama Pompa Hidram dan Fungsinya}

\section{Katup Buang (Waste Valve)}

Katup buang merupakan salah satu komponen terpenting pompa hidram, oleh sebab itu katup limbah harus dirancang dengan baik sehingga berat dan gerakannya dapat disesuaikan. Katup buang sendiri berfungsi untuk mengubah energi kinetik fluida kerja yang mengalir melalui pipa pemasukan menjadi energi tekanan dinamis fluida yang akan menaikkan fluida kerja menuju tabung udara. Beberapa desain katup buang yang sering digunakan diantaranya:

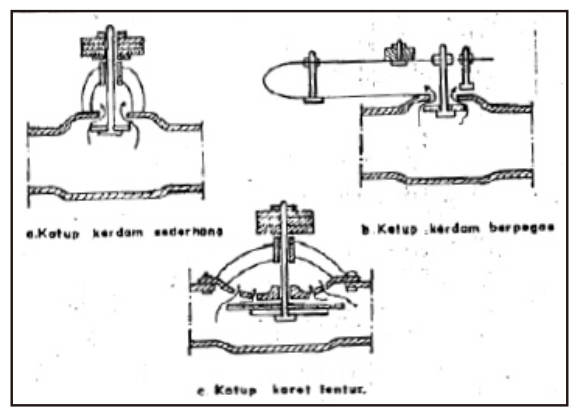

Gambar 3. Contoh Desain Katup Limbah (De Longh dan Hanafie, 1979). 
Katup buang dengan beban yang berat dan panjang langkah yang cukup jauh memungkinkan fluida mengalir lebih cepat, sehingga saat katup buang menutup, akan terjadi lonjakan tekanan yang cukup tinggi, yang dapat mengakibatkan fluida kerja terangkat menuju tabung udara. Sedangkan katup buang dengan beban ringan dan panjang langka lebih pendek, memungkinkan terjadinya denyutan yang lebih cepat sehingga debit air yang terangkat akan lebih besar dengan lonjakan tekanan yang lebih kecil.

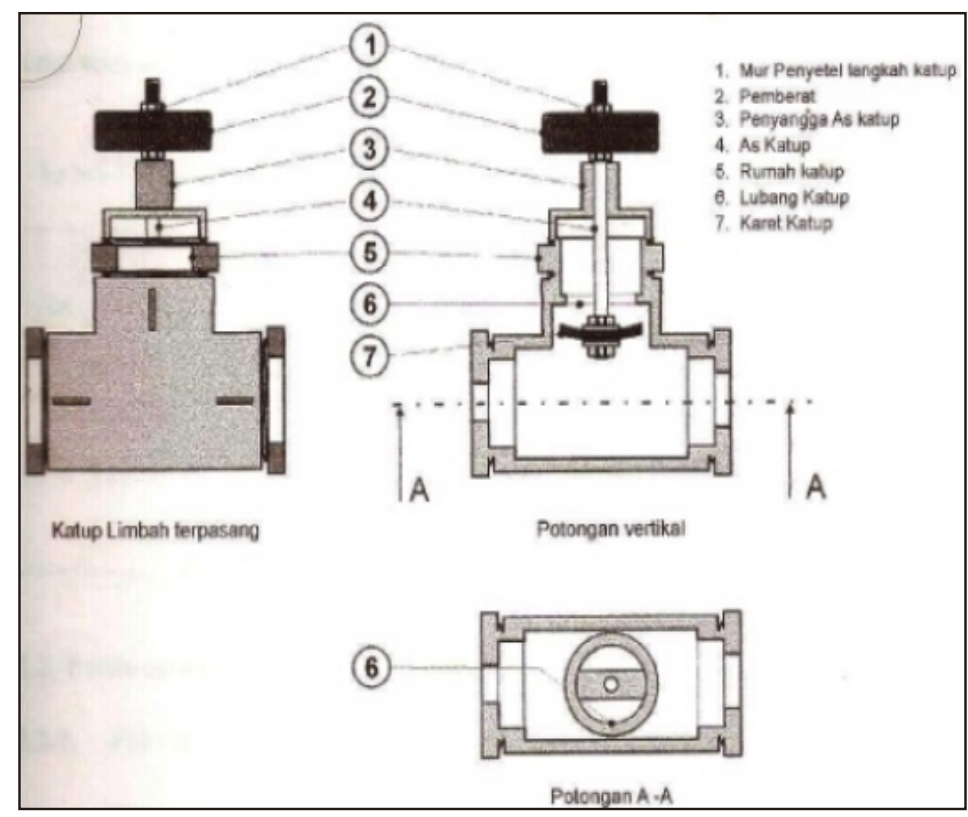

Gambar 4. Komponen katup buang jenis kerdam (De Longh dan Hanafie, 1979).

Adapun bagian - bagian sebuah katup buang dapat dilihat dari gambar dibawah ini:

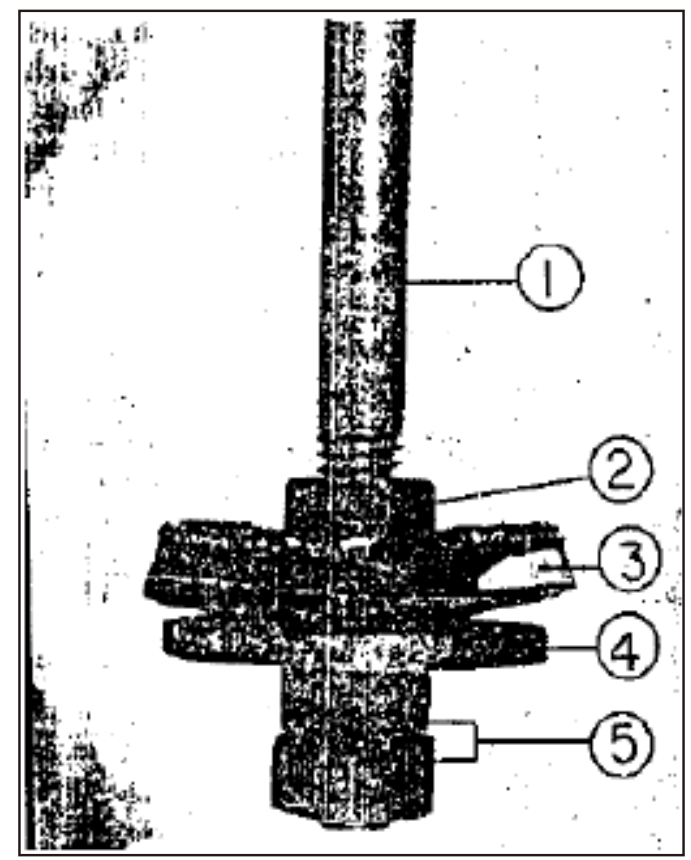

Gambar 5. Bagian - Bagian Katup Buang (De Longh dan Hanafie, 1979). 
Keterangan gambar :

1) Tangkai Katup

2) Mur PenjepitAtas

3) Karet Katup

4) Plat Katup

5) Mur Penjepit Bawah

\section{Katup Penghantar (Delivery Valve)}

Katup penghantar adalah sebuah katup satu arah yang berfungsi untuk menghantarkan air dari badan hidram menuju tabung udara untuk selanjutnya dinaikkan menuju tangki penampungan. Katup penghantar harus dibuat satu arah agar air yang telah masuk ke dalam tabung udara tidak dapat kembali lagi ke dalam badan hidram. Katup penghantar harus mempunyai lubang yang besar sehingga memungkinkan air yang dipompa memasuki ruang udara tanpa hambatan pada aliran (Hanafie dan De Longh, 1979).

\section{Tabung Udara (Air Chamber)}

Tabung udara harus dibuat dengan perhitungan yang tepat, karena tabung udara digunakan untuk memampatkan udara di dalamnya dan untuk menahan tekanan dari siklus ram. Selain itu, dengan adanya tabung udara memungkinkan air melewati pipa penghantar secara kontinyu. Jika tabung udara penuh terisi air, tabung udara akan bergetar hebat, dapat menyebabkan tabung udara pecah. Jika terjadi kasus demikian, ram harus segera dihentikan.

\section{Katup Udara (Air Valve)}

Udara dalam tabung udara, secara perlahan - lahan akan ikut terbawa ke dalam pipa penghantar karena pengaruh turbulensi air. Akibatnya, udara dalam pipa perlu diganti dengan udara baru melalui katup udara. Ukuran katup udara harus disesuaikan sehingga hanya mengeluarkan semprotan air yang kecil setiap kali langkah kompresi. Jika katup udara terlalu besar, udara yang masuk akan terlampau banyak dan ram hanya akan memompa udara. Namun jika katup udara kurang besar, udara yang masuk terlampau sedikit, ram akan bergetar hebat, memungkinkan tabung udara pecah. Oleh karena itu, katup udara harus memiliki ukuran yang tepat.

\section{Pipa Masuk (Driven Pipe)}

Pipa masuk adalah bagian yang sangat penting dari sebuah pompa hidram. Dimensi pipa masuk harus diperhitungkan dengan cermat, karena sebuah pipa masuk harus dapat menahan tekanan tinggi yang disebabkan oleh menutupnya katup buang secara tiba-tiba.

Masalah prioritas digunakan sebagai metode penelitian. Pendekatan dengan jalan diskusi dipilih sebagai alat pemecah permasalahan. Ada tiga masalah prioritas dalam komunitas tersebut, antara lain:

a) Masyarakat membutuhkan pompa yang dapat bertahan lama dan terus beroperasi

b) Pemeliharaan dan operasional dengan biaya rendah dan mudah

c) Kebutuhan akan peningkatkan manajemen

\section{Langkah-langkah proses penelitian:}

a) Kunjungan, sebagai bagian dari pendekatan langsung kepada masyarakat. Pendekatan ini digunakan untuk mencari tahu apa yang dibutuhkan komunitas. Bersamaan dengan itu, studi literatur dan pendekatan diskusi juga dilaksanakan. 
b) Pendekatan diskusi, institusi dan komunitas saling berbagi setiap fungsi, kebutuhan, masalah, bagaimana memecahkan masalah dan program keberlanjutan.

c) Studi literatur, perlu mendukung pembenaran teoritis dan kasus apa pun di masyarakat.

d) Mengumpulkan data, setiap data diperoleh dari setiap diskusi dan tinjauan lapangan. Para ahli akan menganalisa setiap kemungkinan dan kesimpulan masalah.

e) Pengolahan data, ketika semua data selesai, para ahli dari masing-masing bidang akan berdiskusi secara simultan; menetapkan semua prosedur dan manajemen.

f) Kesimpulan.

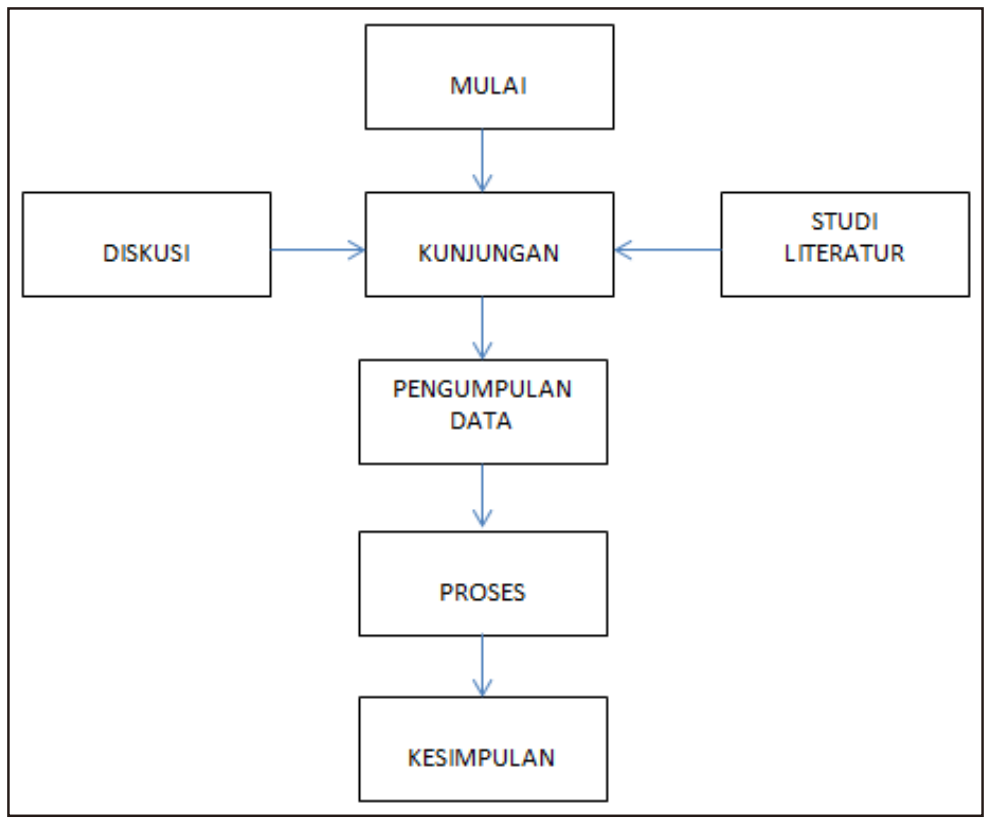

Gambar 6. Diagram Alir Penelitian

\section{Bidang Teknologi}

- Koordinasi dan Diskusi Ngadireso.

Koordinasi dan diskusi tentang pelaksanaan kegiatan pengabdian masyarakat di Dusun

- Pelatihan Perbaikan dan Perawatan Pompa Hidram

Pompa Hidram di Dusun Ngadireso ini sejumlah dua pompa, diantaranya dibuat oleh PNPM Mandiri dan Pihak Terkait. Untuk mendapatkan air bersih yang maksimal perlu diadakan sebuah pelatihan perbaikan dan perawatan agar pompa hidram yang ada bisa dimaksimalkan dengan baik dan terus bisa digunakan. Pelatihan dimaksudkan untuk membekali pengelola atau manajemen terhadap teknologi yang diterapkan yaitu pompa hidram dan teknik analisa kerusakan, sehingga pengelola dapat melakukan perawatan kecil dan besar secara mandiri. Selain itu pelatihan juga dimaksudkan untuk mengenalkan cara kerja dan penggunaan alat yang benar.

\section{Bidang Manajemen}

Dalam pengelolaan air bersih hasil dari pompa hidram perlu dilakukan manajemen pengeloaan yang baik dan tepat saaran. Adapun solusi tentang perbaikan manajemen yang akan didiskusikan dan ditawarkan adalah : 
- Pelatihan Manajemen

Pelatihan manajemen dimaksudkan untuk menjelaskan hasil desain kepada pengelola secara utuh, untuk memudahkan jalanya organisasi dan kontinyuitas penyediaan air untuk warga masyarakat Dusun Ngadireso.

\section{HASILDAN PEMBAHASAN}

Pada kegiatan pengabdian yang dilakukan pada warga dusun ngadireso terbagi menjadi 2 (tiga) bidang permasalahan yang menjadi prioritas tim pelaksana yaitu permasalahan bidang Perbaikan dan Perawatan Pompa Hidram, permasalahan bidang Manajemen Pengelolaan. Evaluasi setiap penyelesaian masalah pada masing-masing bidang dilakukan pada akhir kegiatan program. Evaluasi ini untuk melihat perkembangan kemajuan dari perbaikan pada masing-masing bidang, sehingga akan dapat dilihat perbedaan sebelum dan sesudah pelaksanaan program.

Dari kegiatan pengabdian yang dilakukan maka akan menghasilkan keberlanjutan program yaitu pelatihan padaberbagai bidang dalam mendukung peningkatan kesejahteraan warga dusun Ngadireso, Poncokusumo, Kabupaten Malang.

\section{DAMPAKDAN MANFAAT}

\section{Dampak:}

1. Peningkatan terhadap manajemen dan perawatan pompa hidram

2. Debit air yang melimpah

\section{Manfaat :}

1. Warga desa mampu mengatur debit yang ditransfer di masing-masing rumah

2. Warga desa mampu melakukan perawatan secara intensif dan mengurangi biaya berlebih

\section{KESIMPULAN}

1. Dengan dilakukannya program perawatan dan pemeliharaan pompa hidram secara berkelanjutan akan megurangi biaya lebih dari perawatan pompa hidram dan mengurangi tingkat kerusakan yang berlebihan.

2. Program Pelatihan pompa hidram mampu memberikan pemahaman dan skill yang lebih baik buat masyarakat dalam memelihara pompa hidram.

\section{REFERENSI}

Haidir, Moh.Didi; Namara,Idi; Chayati,Nurul; M,Fadhila; 2016; Manajemen Pengelolaan Kualitas Air Sungai Cisadane dari Aspek Kelembagaan; Jurnal UMJ: Seminar Nasional Sains dan Teknologi; Fakultas Teknik Universitas Muhammadiyah Jakarta

N S M Hussin, S A Gamil, N A M Amin, M J A Safar, M S A Majid, M N F M Kazim, N F M Nasir; 2017; Design and Analysis of Hydraulic Ram Water Pumping System; School of Mechatronic Engineering, Pauh Putra Main Campus, University Malaysia; Journal of Physic: conference series 908012052

Siswatu, Muji; Syafrudin; Sriyana; 2016; Uji Kriteria Manajeman Dalam Pengelolaan Air Limbah Domestik Terpusat; jurnal Media Komunikasi Teknik Sipil, 77-90; Universitas Diponegoro, Semarang

Panduan Pelaksanaan Penelitian dan Pengabdian Kepada Masyarakat Edisi X Tahun 2016 http://5302414086.blogspot.co.id/2015/09/pengertian-mebel-dan-furniture.html https://id.wikipedia.org/wiki/Pemasaran 